\title{
LEVELS AND CORRELATES OF AWARENESS OF POINT-OF-PURCHASE TOBACCO DISPLAYS AND ADVERTISING.
}

\author{
Abraham K. Brown for International Tobacco Control (ITC) collaboration \\ Division of Marketing, Nottingham Business School, Nottingham Trent University, \\ Nottingham, NG1 4BU, UK \\ Email: abraham.brown@ntu.ac.uk
}

\begin{abstract}
This study examined smokers' awareness of tobacco displays and advertising at point-ofpurchase (POP), and whether the association between noticing POP tobacco displays with prompted purchase of cigarettes and quit intentions varied by socioeconomic status (SES). Logistic regression analyses undertaken with a sample of 2,272 current smokers (aged 18+) from the Netherlands and the UK, who completed the International Tobacco Control Surveys between July 2010 and June 2011. Results showed that overall 76.9\% of smokers were aware of POP tobacco displays comprising $88.3 \%$ in the UK and $67.4 \%$ in the Netherlands. After adjusting for covariates, younger smokers in both countries were more likely to be prompted to purchase cigarettes than older smokers. In the Netherlands, smokers with low SES were more likely to indicate that noticing tobacco displays and advertising prompted them to purchase cigarettes than those with high SES (OR $=2.34$, $95 \% \mathrm{CI}=1.28-4.27$ ), but UK smokers with low SES were less likely to be prompted to purchase cigarettes $(\mathrm{OR}=.49,95 \% \mathrm{CI}=.25-.95)$. These findings suggest that retail tobacco displays at POP are still noticeable, and affect cigarettes purchased and quit intention, particularly among those in low social groups. Tobacco legislation should aim at putting cigarettes completely out of sight in retail environments.
\end{abstract}

Keywords: Tobacco displays; Adult smoking; POP restrictions.

\section{INTRODUCTION}

Tobacco marketing influences tobacco use (Davis, Gilpin, Loken, Viswanath, and Wakefield, 2008; Hoek, Jones, Edwards, Maubach, Crane, and Youdan, 2011). In the face of increased restrictions on most forms of tobacco marketing, point-of-purchase (POP) promotion has become an important avenue to create brand awareness and recognition among current, former and potential smokers (Hoek, Gifford, Pirikahu, Thomson, and Edwards, 2010; Lavack and Toth, 2006). Despite the tobacco industry's argument that seeing POP tobacco displays simply encourage brand switching among current smokers (Carter, 2003; Carter, Mills, and Donovan, 2009), evidence suggests that POP displays create cigarette awareness and stimulate prompt purchase especially among smokers and recent quitters (Germain, McCarthy, and Wakefield, 2009; Paynter, Edwards, Schluter, and McDuff, 2009; Wakefield, Germain, and Henriksen, 2008). However, less is known about 
whether these effects differ by socioeconomic groups (Carter et al., 2009; Germain et al., 2009; Siahpush, Jones, Singh, Timsina and Martin, 2010).

Given the harmful effects of tobacco use and the dose-response association between visible smoking cues and promptings for cigarette brands (Carter et al., 2006; Donovan, Jancey, and Jones, 2002; Wakefield et al., 2008), there have been calls for comprehensive bans on tobacco marketing, including point-of-purchase promotion (WHO, 2008). In the UK, the Tobacco Advertising and Promotion Act (TAPA), implemented between February 2003 and July 2005, banned most forms of tobacco marketing (Spanopoulos, Ratschen, McNeill, and Britton, 2012). This placed restrictions on print and electronic media advertisements, and on various forms of promotion. However, in-store tobacco promotions remained somewhat unregulated, and displays of tobacco at point-of-purchase as well as in-store advertising, which were restricted to A5 size, became a potent communication channel usually situated in prominent and observable locations. The Health Act (2009) however required the complete removal of tobacco advertising and displays at point-of-purchase in England by April 2012 in supermarkets but not until April 2015 in small shops (Kasza et al., 2011).

In the Netherlands, in 2003 the Tobacco Act prohibited all forms of tobacco advertising and promotions, with a number of significant exceptions (The Dutch Tobacco Act, 2003). Tobacco displays and advertising at POP are permitted in supermarkets, gas stations, book and magazine shops, drug stores, and the hospitality industry via vending machines. On the façade of tobacco retail stores a maximum of 2 squared metres of advertisement is allowed, whereas in-store tobacco products displays are permitted against a neutral background. Tobacco advertisements within the retail environment are restricted to the area where tobacco products are displayed and may only target people at the point-of-purchase. Although restrictions take different forms the overall level of the POP restriction has been classified as the same in both countries as of July 2010 (Joossens and Raw, 2010). Drawing from the UK and Netherlands data therefore provide some basis to understand how POP tobacco displays and signs act as a promotional tool for smoking.

Despite studies showing association between exposure to cigarette displays and impulse purchase behaviour (Germain et al., 2009; Wakefield et al., 2008), there is limited research on whether influence of retail tobacco displays on adult smokers' purchase and smoking behaviour differ by social grade, particularly among current smokers in European countries (Burton, Clark, and Jackson, 2011; Carter et al., 2009; Wakefield et al., 2008). An Australian study found that the influence of POP tobacco displays on unplanned purchasers was apparent for both sexes and across all socioeconomic groups (Carter et al., 2009). This study adds to the tobacco control literature by examining whether the association between noticing POP tobacco displays and advertising with prompted purchase of cigarettes or quit intentions differ by smokers' socioeconomic status (SES). Specifically, the present study addressed three questions: (1) what was the level of awareness of tobacco advertising and displays at POP in both countries, and were there variations by SES groups? (2) were there any associations between noticing POP tobacco displays and advertising with prompted purchase of cigarettes? and (3) did smokers' socioeconomic status interact with the relationship between noticing tobacco displays and advertising at POP and quit intentions?

\section{METHODS}




\section{Sample}

The sample was adult smokers only (aged 18 and older) who were interviewed in a multicohort study as part of the International Tobacco Control (ITC) Europe survey. Cohort members from the UK are recruited by geographically stratified probability sampling, and surveyed via computer assisted telephone interview (CATI). In the Netherlands, participants were surveyed via computer assisted web interviewing (CAWI). The Netherlands web sample was drawn from a large probability-based database with respondents indicating their willingness to participate in research on a regular basis (Nagelhout, Willemsen, Thompson, Fong, Van den Putte, and de Vries, 2010). Apart from the UK wave 8 data, respondents lost to attrition are replenished by recruiting additional participants at each wave. Despite the lack of replenishment in the UK wave 8 data, the sample is fairly representative of the smoker population on account that replenishment samples are generally not recruited at random. A full description of the ITC project conceptual framework and methods can be found elsewhere (Fong et al., 2006; Thompson et al., 2006). Only current smokers are included in this study, comprising respondents who reported 'daily', 'weekly' or 'monthly' smoking and who have smoked at least 100 cigarettes in their lifetime.

In the two countries the survey was conducted after the implementation of the Tobacco Advertising and Promotion ban. However, tobacco displays at point-of-purchase were still permitted in both countries when the surveys occurred. To permit comparisons of smokers' reported awareness of tobacco displays and advertising at point-of-purchase, waves occurring at similar times are selected. Therefore data from wave eight in the UK, which was collected between July 2010 and June 2011, and data from wave five in the Netherlands, which was obtained between May and June 2011 were utilized in the analyses.

The study was approved by the Institutional Review Board or Research Ethics Board at the University of Stirling (Scotland), the Open University (UK), and the University of Waterloo (Canada). The ITC Netherlands Survey was cleared for ethics by the Central Committee on Research Involving Human Subjects in the Netherlands.

\section{MEASURES \\ Awareness of point-of-purchase tobacco advertising and displays}

Current smokers were asked two specific questions about their awareness of tobacco displays and signs in stores or shops: 'In the last month, have you seen cigarette packages being displayed, including on shelves or on the counter?' (also termed POP tobacco displays) and 'In the last month, have you seen any signs or pictures or other things like clocks with cigarette brands or logos inside shops or stores?' (POP tobacco advertising). Responses to both questions were dichotomised: (1) 'yes' and (0) 'no'.

\section{Perceptions that noticing POP tobacco displays and advertising prompted respondents to buy cigarettes}

One item was used to assess whether tobacco packs or signs at POP prompted respondents to buy cigarettes: 'have you ended up buying cigarettes because you noticed cigarette packs displayed in the store or other signs that cigarettes were sold there? Responses were dichotomised as: (1) yes: comprising 'yes, this happened once', 'yes, this happened twice' and 'yes, this happened more often' and (0) no, this did not happen. 


\title{
Intention to quit
}

A four-point scale based on the stages of change (de Vries and Mudde, 1998; Prochaska, Redding, and Evers, 1997) was used to capture quit intentions and for analyses was dichotomised to determine whether or not smokers have any intention to quit in the next six months.

\section{Covariates}

Control variables were country of residence, age, sex, heaviness of smoking index (HSI) (categorised as: $0-1=$ low, $2-3=$ moderate, and 4-6 = high), and socioeconomic status of respondents, which comprised education and income. These two indicators were categorised into three levels (low, moderate, and high) respectively, and were only partly comparable across the two countries because of differences in educational systems and income levels. Consistent with Kasza et al. (2011), a three-category indicator of SES was created in this order: if both education and income were low, then SES was defined as low, if either education or income was low, then SES was defined as moderate, and if neither education nor income were low, then SES was defined as high. Participants who responded to only one of the two items were included in the SES category called for by the answered item. Those who did not respond to any of the items were excluded from SES-specific analyses.

\begin{abstract}
ANALYSES
A sample of 2,272 participants consisting of 1,295 current smokers from the Netherlands and 977 current smokers from the UK was used in the analyses. All analyses were based on weighted data to ensure that the sample is represented in proportion to the target population in both countries. Logistic regression models were performed for each country (and the combined countries) to examine the association between the outcome variables of interest and the above mentioned covariates. In some logistic analyses, socioeconomic status was used as a covariate as well as an interaction variable with awareness of cigarette packages being displayed and signs. Separate logistic analyses were performed for all models with interaction effects. Data analyses were performed using IBM SPSS version 19.
\end{abstract}

\section{RESULTS}

The sample characteristics of current smokers in the two study countries (data not shown) suggested that both samples were evenly distributed with respect to gender (chi-squared test $\left.\left[\chi^{2}\right](1)=2.21, p=.14\right)$ and age $\left(\chi^{2}(3)=1.92, p=.59\right)$. However, those in the Netherlands were more of moderate socioeconomic status whereas smokers in the UK were more of low socioeconomic groups $\left(\chi^{2}(2)=122.58, p<.001\right)$.

\section{Noticing or salience of point-of-purchase tobacco displays and advertising}

As depicted in table 1, logistic regression analysis was performed to examine whether current smokers' awareness of POP tobacco displays varied by country, age, sex, heaviness of smoking index (HSI) and socioeconomic status. In total, $76.9 \%$ of smokers were aware of POP tobacco displays: $88.3 \%$ in the UK compared to $67.4 \%$ in the Netherlands (Odds Ratio $(\mathrm{OR})=.38,95 \%$ Confidence Interval $(\mathrm{CI})=.20-.42)$. 
Socio-demographic variations emerged in the respective countries. In the UK, smokers with low socioeconomic status were less likely to report salience of POP tobacco displays than those with high socioeconomic status $(\mathrm{OR}=.36,95 \% \mathrm{CI}=.18-.73)$, but salience was evenly balanced among Dutch smokers with low and high SES. In both countries, no significant association was observed by age, sex and heaviness of smoking index. However, smokers of low SES overall were less likely than those of high SES to notice tobacco displays $(\mathrm{OR}=.64,95 \% \mathrm{CI}=.42-.97)$.

\section{TABLE 1}

\section{DEMOGRAPHIC CHARACTERISTICS OF PARTICIPANTS NOTICING POINT- OF-PURCHASE TOBACCO DISPLAYS BY COUNTRY}

\begin{tabular}{|c|c|c|c|c|c|}
\hline & \multicolumn{4}{|c|}{ Noticing cigarette pack displays } & \multirow{3}{*}{$\begin{array}{c}\begin{array}{c}\text { Overall } \\
(76.9 \%)\end{array} \\
\text { OR }[95 \% \mathrm{CI}]\end{array}$} \\
\hline & \multicolumn{2}{|c|}{$\begin{array}{l}\text { Netherlands (W5) } \\
n=1168\end{array}$} & \multicolumn{2}{|c|}{$\begin{array}{l}\text { United Kingdom }(\mathbf{W} 8) \\
n=970\end{array}$} & \\
\hline Variables & n(\%) & OR $[95 \% \mathrm{CI}]$ & n(\%) & OR $[95 \% \mathrm{CI}]$ & \\
\hline Overall & $787(67.4)$ & & $875(88.3)$ & & \\
\hline NL vs. UK & & & & & $.38^{* * *}(.20-.42)$ \\
\hline \multicolumn{6}{|l|}{ Age } \\
\hline $18-24$ & 87 (64.0) & $.88(.57-1.36)$ & $117(92.1)$ & $1.57(.73-3.40)$ & $1.02(.70-1.47)$ \\
\hline $25-39$ & $209(68.1)$ & $1.02(.69-1.43)$ & $252(87.5)$ & $.73(.43-1.26)$ & $.91(.67-1.22)$ \\
\hline $40-54$ & $268(69.6)$ & $1.20(.86-1.67)$ & $274(87.5)$ & $.87(.52-1.48)$ & $1.09(.82-1.45)$ \\
\hline $55+$ & $192(65.8)$ & Ref & $214(88.1)$ & Ref & Ref \\
\hline \multicolumn{6}{|l|}{ Sex } \\
\hline Male (M) & $406(66.0)$ & Ref & $428(87.9)$ & Ref & Ref \\
\hline Female $(\mathrm{F})$ & $380(68.8)$ & $1.13(.87-1.46)$ & $429(88.6)$ & $1.08(.73-1.62)$ & $1.19(.73-1.98)$ \\
\hline \multicolumn{6}{|l|}{ SES } \\
\hline Low & $245(63.5)$ & $.72(.50-1.04)$ & $468(85.7)$ & $.36^{* *}(.18-.73)$ & $.64^{*}(.42-.97)$ \\
\hline Moderate & $354(69.0)$ & $.91(.65-1.28)$ & $233(90.0)$ & $.57(.26-1.24)$ & $.91(.59-1.40)$ \\
\hline High & $185(70.6)$ & Ref & $156(94.0)$ & Ref & Ref \\
\hline \multicolumn{6}{|l|}{ HSI } \\
\hline Low & $227(69.2)$ & $1.03(.74-1.44)$ & $147(89.1)$ & $1.14(.60-2.16)$ & $1.02(.76-1.37)$ \\
\hline Moderate & $261(65.6)$ & $.90(.66-1.22)$ & 499 (88.5) & $1.13(.70-1.83)$ & $.94(.73-1.22)$ \\
\hline High & $271(67.9)$ & Ref & $188(87.0)$ & Ref & Ref \\
\hline
\end{tabular}

Notes: ${ }^{*} \mathrm{P}<.05,{ }^{* * *} \mathrm{P}<.01,{ }^{* * * *} \mathrm{P}<.001 . \mathrm{OR}=$ Odds Ratio; $\mathrm{CI}=$ Confidence Interval. Ref = Reference category. Analyses are based on weighted data. Noticing and salience have been used interchangeably.

In terms of noticing POP tobacco advertising (table 2), overall 15.7\% of smokers reported being aware, but this varied by country; $22.2 \%$ of smokers in the UK noticed POP tobacco advertising compared to $9.7 \%$ in the Netherlands $(\mathrm{OR}=.32,95 \% \mathrm{CI}=.24-.43)$. 
Comparison by socio-demographics showed that in the UK, smokers aged 25-39 were more likely to notice POP tobacco advertising than their older counterparts aged 55+ years (OR $=1.71,95 \% \mathrm{CI}=1.10-2.67$ ), whereas in the Netherlands salience was uniformly balanced by age. In both countries, females were less likely to report salience of POP tobacco advertising than males $(\mathrm{NL}: \mathrm{OR}=.52,95 \% \mathrm{CI}=.33-.82$, and $\mathrm{UK}: \mathrm{OR}=.54,95 \% \mathrm{CI}=$ $.40-.75)$. Smokers in the Netherlands with low socioeconomic status were less likely to notice POP tobacco advertising than those with high SES ( $\mathrm{OR}=.43,95 \% \mathrm{CI}=.23-.82$ ), whereas salience was evenly balanced among UK smokers with low and high SES. In the Netherlands, smokers with low scores on HSI were less likely to report salience of POP tobacco advertising than those with high $\mathrm{HSI}(\mathrm{OR}=.46,95 \% \mathrm{CI}=.25-.85)$. However, in the UK, salience was greater among smokers with low HSI than those with high HSI (OR $=1.93,95 \% \mathrm{CI}=1.19-3.14)$.

Overall salience of tobacco advertising was more likely among smokers aged 25-39 than those aged $55+(\mathrm{OR}=1.67,95 \% \mathrm{CI}=1.16-2.30)$. Females were less likely to notice POP advertising overall than males ( $\mathrm{OR}=.55,95 \% \mathrm{CI}=.42-.71)$, whereas those with low SES were less likely to notice tobacco advertising in stores than smokers with high SES (OR = $.67,95 \% \mathrm{CI}=.47-.94)$.

TABLE 2

DEMOGRAPHIC CHARACTERISTICS OF PARTICIPANTS NOTICING POINTOF-PURCHASE TOBACCO ADVERTISING BY COUNTRY

\begin{tabular}{|c|c|c|c|c|c|}
\hline \multirow[b]{3}{*}{ Variables } & \multicolumn{4}{|c|}{ Noticing signs/pictures in stores } & \multirow{3}{*}{$\begin{array}{c}\begin{array}{c}\text { Overall } \\
15.7 \%\end{array} \\
\text { OR }[95 \% \mathrm{CI}]\end{array}$} \\
\hline & \multicolumn{2}{|c|}{$\begin{array}{l}\text { Netherlands (W5) } \\
n=1045\end{array}$} & \multicolumn{2}{|c|}{$\begin{array}{l}\text { United Kingdom }(\mathrm{W} 8) \\
\mathrm{n}=971\end{array}$} & \\
\hline & n (\%) & OR $[95 \%$ CI $]$ & OR $[95 \% \mathrm{CI}]$ & OR $[95 \% \mathrm{CI}]$ & \\
\hline Overall & $101(9.7)$ & & $215(22.2)$ & & \\
\hline NL vs. UK & & & & & $.32^{* * *}(.24-.43)$ \\
\hline \multicolumn{6}{|l|}{ Age } \\
\hline $18-24$ & $15(12.4)$ & $1.82(.85-3.91)$ & $25(19.7)$ & $1.21(.69-2.12)$ & $1.34(.85-2.09)$ \\
\hline $25-39$ & $30(11.1)$ & $1.53(.81-2.88)$ & $78(27.2)$ & $1.71^{*}(1.10-2.67)$ & $1.67^{* *}(1.16-2.30)$ \\
\hline $40-54$ & $33(9.5)$ & $1.23(.66-2.89)$ & $71(22.7)$ & $1.40(.90-2.17)$ & $1.33(.93-1.90)$ \\
\hline $55+$ & $17(6.4)$ & Ref & $41(17.0)$ & Ref & Ref \\
\hline \multicolumn{6}{|l|}{ Sex } \\
\hline Male & $65(11.8)$ & Ref & $135(27.8)$ & Ref & Ref \\
\hline Female & $36(7.3)$ & $.52^{* *}(.33-.82)$ & $81(16.7)$ & $.54^{* * *}(.40-.75)$ & $.55^{* * *}(.42-.71)$ \\
\hline \multicolumn{6}{|l|}{ SES } \\
\hline Low & $23(6.7)$ & $.43^{*}(.23-.82)$ & $109(20.0)$ & $.77(.50-1.18)$ & $.67^{*}(.47-.94)$ \\
\hline Moderate & $49(10.5)$ & $.79(.47-1.34)$ & $57(22.2)$ & $.85(.53-1.36)$ & $.85(.60-1.20)$ \\
\hline High & $26(11.4)$ & Ref & $48(29.3)$ & Ref & Ref \\
\hline HSI & & & & & \\
\hline
\end{tabular}




\begin{tabular}{|c|c|c|c|c|c|}
\hline Low & $20(6.8)$ & $.46^{*}(.25-.85)$ & $54(32.7)$ & $1.93^{* *}(1.19-3.14)$ & $1.10(.76-1.58)$ \\
\hline Moderate & $37(10.2)$ & $.79(.48-1.30)$ & $114(20.2)$ & $1.06(.71-1.59)$ & $.90(.66-1.22)$ \\
\hline High & $41(11.7)$ & $R e f$ & $41(19.1)$ & $R e f$ & $R e f$ \\
\hline
\end{tabular}

Notes: ${ }^{*} \mathrm{P}<.05,{ }^{* *} \mathrm{P}<.01,{ }^{* * *} \mathrm{P}<.001$. OR= Odds Ratio; $\mathrm{CI}=$ Confidence Interval. Ref $=$ Refers to reference category. Analyses are based on weighted data. Noticing and salience have been used interchangeably.

\section{Relationship between noticing tobacco displays and advertising at POP and promptings to purchase cigarettes}

Table 3 presents current smokers' responses regarding whether noticing tobacco displays and advertisements at POP prompted them to buy cigarettes. Overall, $10.1 \%$ of current smokers reported that being aware of tobacco displays and advertising at POP prompted cigarette purchases: $6.4 \%$ of UK smokers compared to $13.3 \%$ of Dutch smokers $(\mathrm{OR}=$ $2.47,95 \% \mathrm{CI}=1.72-3.45)$.

TABLE 3

SAMPLE CHARACTERISTICS OF PARTICIPANTS WHO WERE PROMPTED TO PURCHASE CIGARETTES

\begin{tabular}{|c|c|c|c|c|c|}
\hline \multirow[b]{3}{*}{ Variables } & \multicolumn{4}{|c|}{ Displays prompted purchase of cigarettes } & \multirow{3}{*}{$\begin{array}{c}\text { Overall } \\
10.1 \% \\
\text { OR }[95 \% \mathrm{CI}]\end{array}$} \\
\hline & \multicolumn{2}{|c|}{$\begin{array}{c}\begin{array}{c}\text { Netherlands (W5) } \\
\mathrm{n}=152\end{array} \\
\end{array}$} & \multicolumn{2}{|c|}{$\begin{array}{c}\text { United Kingdom (W 8) } \\
n=63\end{array}$} & \\
\hline & n (\%) & OR $[95 \% \mathrm{CI}]$ & n (\%) & OR $[95 \% \mathrm{CI}]$ & \\
\hline Overall & $152(13.3)$ & & $63(6.4)$ & & \\
\hline NL vs. UK & & & & & $2.47^{* * * *}(1.72-3.45)$ \\
\hline \multicolumn{6}{|l|}{ Age } \\
\hline $18-24$ & $30(23.8)$ & $2.60^{* *}(1.47-4.59)$ & $13(10.3)$ & $4.13^{* *}(1.58-7.80)$ & $2.68^{* * *}(1.67-4.30)$ \\
\hline $25-39$ & $36(12.2)$ & $1.21(.71-2.06)$ & $22(7.6)$ & $2.52^{*}(1.02-6.19)$ & $1.42(.92-2.21)$ \\
\hline $40-54$ & $45(11.9)$ & $.97(.59-1.61)$ & $21(6.7)$ & $2.27(.92-5.59)$ & $1.21(.79-1.85)$ \\
\hline $55+$ & $33(11.1)$ & Ref & $7(2.9)$ & Ref & Ref \\
\hline \multicolumn{6}{|l|}{ Sex } \\
\hline Male & $82(13.9)$ & Ref & $33(6.8)$ & Ref & Ref \\
\hline Female & $70(12.7)$ & $.90(.71-1.50)$ & $30(6.2)$ & $.98(.58-1.66)$ & $.98(.73-1.32)$ \\
\hline \multicolumn{6}{|l|}{ SES } \\
\hline Low & $49(13.1)$ & $2.34^{* *}(1.28-4.27)$ & $26(4.8)$ & $.49^{*}(.25-.95)$ & $1.27(.81-2.01)$ \\
\hline Moderate & $81(16.2)$ & $2.70^{* * *}(1.56-4.67)$ & $19(7.4)$ & $.75(.37-1.51)$ & $1.72^{*}(1.12-2.62)$ \\
\hline High & $21(8.1)$ & Ref & $17(10.2)$ & Ref & Ref \\
\hline \multicolumn{6}{|l|}{ HSI } \\
\hline Low & $53(16.2)$ & $2.20^{* *}(1.33-3.62)$ & $13(7.9)$ & $1.40(.61-3.21)$ & $1.89^{* *}(1.23-2.88)$ \\
\hline Moderate & $60(15.5)$ & $2.05^{* *}(1.27-3.29)$ & $36(6.4)$ & $1.10(.56-2.19)$ & $1.67^{*}(1.13-2.47)$ \\
\hline High & $34(8.9)$ & Ref & $12(5.6)$ & Ref & Ref \\
\hline
\end{tabular}




\begin{tabular}{|c|c|c|c|c|c|}
\hline Noticed Displays & & & & & \\
\hline Yes & $109(14.5)$ & $1.32(.87-1.99)$ & $55(6.4)$ & $.87(.39-1.97)$ & $1.20(.83-1.74)$ \\
\hline Noticed Signs/Ads & & & & & \\
\hline Yes & $19(20.2)$ & $1.36(.72-2.57)$ & $16(7.4)$ & $1.07(.57-1.99)$ & $1.21(.78-1.87)$ \\
\hline
\end{tabular}

Notes: ${ }^{*} \mathrm{P}<.05,{ }^{* *} \mathrm{P}<.01,{ }^{* * *} \mathrm{P}<.001 . \mathrm{OR}=$ Odds Ratio; $\mathrm{CI}=$ Confidence Interval. Ref= Reference category. SES (L) and SES (M) signify respondents with low and moderate socioeconomic status respectively. Analyses are based on weighted data.

In the respective countries, younger smokers aged 18-24 years were more likely to report that noticing tobacco displays and advertisements prompted them to purchase cigarettes than those aged 55+ (NL: OR $=2.60,95 \% \mathrm{CI}=1.47-4.59$, and $\mathrm{UK}: \mathrm{OR}=4.13,95 \% \mathrm{CI}$ $=1.58-7.80)$. Similarly, in the Netherlands, smokers with low and moderate SES were more likely to indicate that noticing tobacco displays and advertising prompted them to purchase cigarettes than those with high $\mathrm{SES}(\mathrm{OR}=2.34,95 \% \mathrm{CI}=1.28-4.27$, and $\mathrm{OR}=$ $2.70,95 \% \mathrm{CI}=1.56-4.67$, respectively), whereas noticeability was less likely among smokers with low SES in the UK compared to those with high SES (OR $=.49,95 \% \mathrm{CI}=$ $.25-.95)$. In the Netherlands, and not in the UK, smokers with low and moderate scores on HSI were more likely to indicate that noticing tobacco displays and advertisements prompted them to purchase cigarettes than those with high $\mathrm{HSI}(\mathrm{OR}=2.20,95 \% \mathrm{CI}=1.33$ -3.62 , and $\mathrm{OR}=2.05,95 \% \mathrm{CI}=1.27-3.29$ ) respectively. For these models no association with gender and seeing tobacco displays and signs in both countries were found.

Overall, younger smokers aged 18-24 who noticed tobacco displays and advertisements were more likely to be prompted to purchase cigarettes than those aged $55+$ years $(\mathrm{OR}=$ $2.68,95 \% \mathrm{CI}=1.67$ - 4.30). Smokers with moderate SES overall who noticed POP tobacco displays and advertising were more likely to be prompted to purchase cigarettes than smokers with high SES (OR $=1.72,95 \% \mathrm{CI}=1.12-2.62)$, whereas those with low and moderate scores on HSI were more likely to be prompted to purchase cigarette than those with high scores on $\mathrm{HSI}(\mathrm{OR}=1.89,95 \% \mathrm{CI}=1.23-2.88$, and $\mathrm{OR}=1.67,95 \% \mathrm{CI}=1.13$ $-2.47)$.

\section{Noticing tobacco displays and advertising at POP and intention to quit}

As shown in table 4, 28.7\% of current smokers intended to quit smoking within the next 6 months, with variation by country; $25.8 \%$ in the Netherlands compared to $31.6 \%$ of UK smokers $(\mathrm{OR}=.66,95 \% \mathrm{CI}=.52-.84)$. 
TABLE 4

ASSOCIATION BETWEEN QUIT INTENTION AND NOTICING POINT-OFPURCHASE TOBACCO DISPLAYS OR ADVERTISING BY COUNTRY

\begin{tabular}{|c|c|c|c|c|c|}
\hline \multirow[b]{3}{*}{ Variables } & \multicolumn{4}{|c|}{ Intention to quit } & \multirow{3}{*}{$\begin{array}{l}\text { Overall } \\
28.7 \% \\
\text { OR [95\% CI] }\end{array}$} \\
\hline & \multicolumn{2}{|c|}{$\begin{array}{l}\text { Netherlands (W5) } \\
\mathrm{n}=\mathbf{2 6 2}\end{array}$} & \multicolumn{2}{|c|}{$\begin{array}{l}\text { United Kingdom (W 8) } \\
\mathrm{n}=306\end{array}$} & \\
\hline & n (\%) & OR $[95 \% \mathrm{CI}]$ & n (\%) & OR $[95 \% \mathrm{CI}]$ & \\
\hline Overall & $262(25.8)$ & & $306(31.6)$ & & \\
\hline NL vs. UK & & & & & $.66^{* *}(.52-.84)$ \\
\hline \multicolumn{6}{|l|}{ Age } \\
\hline $18-24$ & $29(26.6)$ & $1.05(.56-1.96)$ & $45(36.0)$ & $1.81^{*}(1.11-2.94)$ & $1.37(.97-1.95)$ \\
\hline $25-39$ & $99(36.9)$ & $2.27^{* *}(1.43-3.61)$ & $110(38.3)$ & $1.61^{*}(1.08-2.40)$ & $.85(.59-1.20)$ \\
\hline $40-54$ & $80(24.4)$ & $1.32(.83-2.09)$ & $88(28.1)$ & $1.12(.75-1.67)$ & $.72(.50-1.05)$ \\
\hline $55+$ & $50(18.7)$ & Ref & $63(26.1)$ & Ref & $\operatorname{Ref}$ \\
\hline \multicolumn{6}{|l|}{ Sex } \\
\hline Male & $141(25.9)$ & Ref & $131(27.1)$ & Ref & Ref \\
\hline Female & $121(25.7)$ & $.94(.70-1.36)$ & $174(36.1)$ & $1.68^{* * * *}(1.26-2.26)$ & $1.33^{* *}(1.07-1.66)$ \\
\hline \multicolumn{6}{|l|}{ SES } \\
\hline Low & $56(16.6)$ & $.32^{* * *}(.20-.52)$ & $147(27.0)$ & $.53^{* *}(.36-.78)$ & $.47^{* * *}(.35-.63)$ \\
\hline Moderate & $123(27.5)$ & $.53^{* *}(.36-.79)$ & $87(33.9)$ & $.72(.47-1.10)$ & $.65^{* *}(.48-.86)$ \\
\hline High & $56(37.2)$ & Ref & $72(43.4)$ & Ref & Ref \\
\hline \multicolumn{6}{|l|}{ HIS } \\
\hline Low & $86(30.0)$ & $1.12(.73-1.72)$ & $82(49.7)$ & $3.18^{* * *}(2.00-5.03)$ & $1.76^{* * *}(1.30-2.39)$ \\
\hline Moderate & $86(24.9)$ & $1.04(.70-1.56)$ & $165(29.4)$ & $1.38(.94-2.01)$ & $1.14(.87-1.49)$ \\
\hline High & $76(22.0)$ & $\overline{R e f}$ & $48(22.2)$ & Ref & Ref \\
\hline Noticed displays (Yes) & $183(28.4)$ & $1.11(.77-1.58)$ & $260(30.5)$ & $.55^{* *}(.36-.85)$ & $.86(.65-1.12)$ \\
\hline Noticed Signs/ads (Yes) & $30(33.7)$ & $1.45(.86-2.43)$ & 74 (34.6) & $1.17(.83-1.67)$ & $.80(.60-1.07)$ \\
\hline \multicolumn{6}{|l|}{ Interaction Variables } \\
\hline Displays x SES (L) & & $.85(.29-2.51)$ & & $.10^{*}(.02-.58)$ & $.38^{*}(.18-.82)$ \\
\hline Displays x SES (M) & & $.94(.37-2.37)$ & & $.33(.05-2.30)$ & $.74(.34-1.60)$ \\
\hline Signs/ads x SES (L) & & $.32(.04-2.38)$ & & $.92(.38-2.25)$ & $1.09(.53-2.28)$ \\
\hline Signs/ads x SES (M) & & $1.52(.47-4.92)$ & & $.64(.23-1.76)$ & $1.06(.51-2.24)$ \\
\hline
\end{tabular}

Notes: ${ }^{*} \mathrm{P}<.05,{ }^{* *} \mathrm{P}<.01,{ }^{* * *} \mathrm{P}<.001 . \mathrm{OR}=$ Odds Ratio; $\mathrm{CI}=$ Confidence Interval. Ref = Reference category. SES (L) and SES (M) signify respondents with low and moderate socioeconomic status respectively. Analyses are based on weighted data.

Demographic comparison suggested that in the respective countries smokers aged 25-39 years were more likely to indicate intentions to quit than those aged 55+ (NL: OR $=2.27$, $95 \% \mathrm{CI}=1.43-3.61$, and $\mathrm{UK}: \mathrm{OR}=1.61,95 \% \mathrm{CI}=1.08-2.40)$, respectively. In the $\mathrm{UK}$, females were more likely than males to intend to quit, but this was comparable in 
Netherlands (UK: $\mathrm{OR}=1.68,95 \% \mathrm{CI}=1.26-2.26$ ). Those with low SES in the UK and the Netherlands were less likely to intend to quit than those with high SES (UK: OR $=.53$, $95 \% \mathrm{CI}=.36-.78$, and NL: OR $=.32,95 \% \mathrm{CI}=.20-.52)$. Smokers in the UK, and not in the Netherlands, who reported low scores on HSI were more likely to indicate intentions to quit smoking (UK: $\mathrm{OR}=3.18,95 \% \mathrm{CI}=2.00-5.03)$. Those in the $\mathrm{UK}$ who noticed POP tobacco displays were less likely to intend to quit $(\mathrm{OR}=.55,95 \% \mathrm{CI}=.36-.85)$, but noticeability was not significantly associated with quit intentions among Dutch smokers.

In terms of interaction effects, smokers in the UK with low SES who noticed tobacco displays were less likely to indicate intentions to quit smoking than those with high SES who noticed displays (UK: OR of interaction with low $\mathrm{SES}=.10,95 \% \mathrm{CI}=.02-.58$ ). No interaction effects were found with respect to smokers in the Netherlands. Nonetheless, overall smokers with low SES who noticed tobacco displays were less likely to intend to quit than those with high SES who noticed displays (OR of interaction with low $\mathrm{SES}=.38$, $95 \% \mathrm{CI}=.18-.82)$.

\section{DISCUSSION}

Although enactment of tobacco marketing regulation has led to reductions in exposure to pro-smoking cues in Europe and elsewhere (Kasza et al., 2011), salience of tobacco displays at point-of-purchase remains prominent among smokers in the Netherlands and UK. Around three quarters of smokers overall were aware of retail tobacco displays, after adjusting for demographic factors. In addition, salience of tobacco advertising in stores, including depictions of cigarette signs or pictures were reported by approximately $16 \%$ of smokers overall, comprising $22.2 \%$ in the UK and $9.7 \%$ in the Netherlands. These results showing relatively low reported awareness of tobacco advertising reflect the limited advertising at point-of-purchase in both countries. In the UK, for instance, in-store tobacco advertising was restricted to depictions of cigarette signs on A5 size, while in the Netherlands tobacco advertisements within the retail environment are limited to the area where tobacco products are displayed. The Netherlands and the UK should therefore, aim to establish legislation that removes tobacco advertising and displays completely from retail outlets.

In total, just over a tenth of smokers indicated that they were prompted to purchase cigarettes as a consequence of noticing retail tobacco displays and advertising, with Dutch smokers $(13.3 \%)$ being more likely to report that salience prompted purchase than their UK counterparts $(6.4 \%)$. Among this group, younger smokers (aged 18-24 years) in the respective countries were more likely to indicate that visible displays of tobacco at POP prompted them to buy cigarettes than older smokers aged 55+. Thus, noticing POP tobacco displays and advertising seem to play a significant role in stimulating prompt purchases of cigarettes, particularly among younger smokers in both countries. Smokers in the UK but not in the Netherlands, who noticed POP tobacco displays were less likely to intend to quit smoking.

This study has important policy implications. First, the level of awareness of tobacco displays at POP in both countries suggest that retail tobacco displays serve as a form of advertising for cigarette brands (Feighery, Ribisl, Clark, and Haladjian, 2003; Wakefield et al., 2008). Hence, unless POP promotions are restricted, the tobacco industry will continue 
to exploit this unregulated channel. Evidence shows that there is a profusion of smoking cues in most retail outlets in several jurisdictions, with tobacco displays positioned at pointof-purchase for maximum salience (Kasza et al., 2011; Wakefield et al., 2008).

Our findings that Dutch smokers of low and moderate socioeconomic status who noticed POP tobacco displays and signs are likely to be prompted to purchase cigarettes, compared to those with high SES, are consistent with research showing that in-store displays may increase sale of consumer products (Carter et al., 2009; Chevalier, 1985; Curhan, 1974). Although in the UK reported salience among those with low SES were rather less likely to be prompted to purchase cigarettes, these findings and others (Kasza et al., 2011; Paul et al., 2010; Wakefield et al., 2008) strengthen the evidence for implementing effective POP marketing regulation by putting tobacco displays and signs out of sight in retail outlets.

Finally, the findings that those who noticed POP tobacco displays in the UK were less likely to indicate quit intentions suggest that salience of retail tobacco displays may discourage smokers from attempting to quit smoking. More so, the findings that overall, salience of POP displays among smokers' with lower socioeconomic groups affected negatively their likelihood of quitting suggest that tobacco displays may undermine quit intentions especially among those in the low social groups. These findings are consistent with studies that found that tobacco advertising might weaken attempts to quit smoking (Basil, Basil, and Schooler, 2000; Wilkinson, Mason, and Paksoy, 1982).

A limitation of the study included use of self-report of noticing tobacco displays and signs as well as promptings to purchase cigarettes, which may be under-reported or over-reported if smokers merely agree with the question asked. It is also possible that 'noticing POP tobacco promotion' is a qualitatively different measure than the more objective measures of exposure to POP tobacco promotion such as store-visiting frequency. Moreover, it was not possible to make causal inferences because cross-sectional data was used. Furthermore, it is important to note that the survey was conducted in countries which have some form of POP advertising restrictions and therefore suggests that POP displays promotion might be even more noticeable in countries without any regulation.

In conclusion, the current results indicate that tobacco displays at point-of-purchase clearly act as a form of advertising on account that these maintain prominence, and affect cigarettes purchased and quit intention, particularly among those in low social groups. These results provide further evidence that support legislation for complete removal of cigarette displays in retail environments as this would reduce exposure and promptings to purchase as well as encourage quit intentions. 


\section{References}

Basil, M. D., Basil, D. Z., \& Schooler, C. (2000). Cigarette advertising to counter new year's resolutions. Journal of Health Communication, 5: 161-174.

Brown \& Williamson. (1975). Brown and Williamson Tobacco Corporation 750000 Marketing Plans. Bates No. 670625569- 670625737. [WWW document]. URL http://tobaccodocuments.org/ bw/253700.html.

Burton, S., Clark, L., \& Jackson, K. (2011). The association between seeing retail displays of tobacco and tobacco smoking and purchase: findings from a diary style survey. Addiction, 107: 169-175.

Carter, S. (2003). Going below the line: creating transportable brands for Australia's dark market. Tobacco Control, 12(Suppl 3):iii87e94.

Carter, O. B. J., Mills, B. W., \& Donovan, R.J. (2009). The effect of retail cigarette pack displays on unplanned purchases: Results from immediate postpurchase interviews. Tobacco Control, 18: 218-221.

Carter, B. L., Robinson, J. D., Lam, C.Y., Wetter, D.W., Tsan, J.Y., Day, S.X., \& Cinciripini, P.M. (2006). A psychometric evaluation of cigarette stimuli used in a cue reactivity study. Nicotine \& Tobacco Research, 8: 361-369.

Chevalier, M. (1985). Increase in sales due to in-store display. Journal of Marketing Research, 12: 426-431.

Curhan, R.C. (1974). The effects of merchandising and temporary promotional activities on the sales of fresh fruits and vegetables in supermarkets. Journal of Marketing Research, 11: 286-294.

Davis, R., Gilpin, E., Loken, B., Viswanath, K., \& Wakefield, M. (2008). Influence of tobacco marketing on smoking behavior. In: Davis R, Gilpin E, Loken B, Viswanath K, Wakefield M, eds. The role of the media in promoting and reducing tobacco use. Tobacco control monograph No.19. Bethesda, Maryland, USA: US Department of Health and Human Services, National Institutes of Health, National Cancer Institute, 211-291.

de Vries, H., \& Mudde, A. N. (1998). Predicting stage transitions for smoking cessation applying the attitude social influence efficacy model. Psychology and Health, 13:369-385.

Donovan, R.J., Jancey, J., \& Jones, S. (2002). Tobacco point of sale advertising increases positive brand user imagery. Tobacco Control, 11: 191-194.

Feighery, E.C., Ribisl, K. M., Clark, P.I., \& Haladjian, H.H. (2003). How tobacco companies ensure prime placement of their advertising and products in stores: interviews with retailers about tobacco company incentive programmes. Tobacco Control, 12: 184188. 
Fong, G. T., Cummings, K. M., Borland, R., Hastings, G., Hyland, A., Giovino, G.A., Hammond, D., \& Thompson, M.E. (2006). The conceptual framework

of the international tobacco control (ITC) policy evaluation project. Tobacco Control, 15(Suppl 3):iii3-11.

Germain, D., McCarthy, M., \& Wakefield, M. (2009).Smoker sensitivity to retail tobacco displays and quitting: a cohort study. Addiction, 105: 159-163.

Hoek J, Gifford H, Pirikahu G, Thomson, D., \& Edwards, R. (2010). How do tobacco retail displays affect cessation attempts? Findings from a qualitative study. Tobacco Control, 19:334-337.

Hoek, J, Jones, A., Edwards, R., Maubach, N., Crane, J., \& Youdan, B., for the ASPIRE 2025 collaboration (2011). Eliminating tobacco point of sale displays: removing the retail detail from the devil. Journal of the New Zealand Medical Association, 124:1345.

Joossens, L. \& Raw, M. (2010). The Tobacco Control Scale 2010 in Europe. Available at: http://www.ensp.org/sites/default/files/TCS_2010_in_Europe_FINAL.pdf.

Kasza, K. A., Hyland, A., Brown, A., Siahpush, M., Yong, H-H., McNeill, A.D., Li, L., $\&$ Cummings, M.K. (2011). The effectiveness of tobacco marketing regulations on reducing smokers' exposure to advertising and promotion: findings from the International Tobacco Control (ITC) Four Country Survey. International Journal of Environmental Research \& Public Health, 8: 321-340.

Lavack, A. M., \& Toth, G. (2006). Tobacco point-of-purchase promotion: examining tobacco industry documents. Tobacco Control, 15:377e84.

Lovato, C., Hsu, H. C., Sabiston, C. M., Hadd, V., \& Nykiforuk, C.I.J. (2007). Tobacco point-of-purchase marketing in school neighbourhoods and school smoking prevalence: A descriptive study. Canadian Journal of Public Health, 98: 265-270.

Nagelhout, G. E., Willemsen, M. C., Thompson, M. E., Fong, G. T., Van den Putte, B., \& De Vries, H. (2010). Is web interviewing a good alternative to telephone interviewing? Findings from the International Tobacco Control (ITC) Netherlands Survey. BMC Public Health, 10: 351.

Paul, C.L., Mee, K.J., Judd, T.M., Walsh, R.A., Tang, A., Penman, A., \& Girgis, A. (2010). Anywhere, anytime: Retail access to tobacco in New South Wales and its potential impact on consumption and quitting. Social Science \& Medicine, 71: 799-806.

Paynter, J., Edwards, R., Schluter, P.J., \& McDuff, I. (2009). Point of sale tobacco displays and smoking amongst $14-15$ year olds in New Zealand: cross sectional study. Tobacco Control, 18: 268-274.

Prochaska, J.O., Redding, C.A., \& Evers, K. (1997). The transtheoretical model and 
stages of change. In K. Glanz , F. M. Lewis, \& B. K. Rimer (Eds.), Health behavior and health education: Theory, research, and practice (pp. 60 - 84), San Francisco, CA : JosseyBass, 1997.

Prohibition of tobacco displays in shops - the regulations in detail. Available: http://www.parliament.uk/briefing-papers/SN05537. Accessed 2011 Aug 4.

Siahpush, M., Jones, P.R., Singh, G.K., Timsina, L.R., \& Martin, J. (2010). The association of tobacco marketing with median income and racial/ethnic characteristics of neighbourhoods in Omaha, Nebraska. Tob. Control, 19: 256-258.

Spanopoulos, D., Ratschen, E., McNeill, A., \& Britton, J. (2012). Retail price and point of sale display of tobacco in the UK: A descriptive study of small retailers. PLoS One, 7:1. The Dutch Tobacco Act.

Available at: http://wetten.overheid.nl/BWBR0004302/geldigheidsdatum_26-09-2011.

Thompson, M. E., Fong, G.T., Hammond, D., Boudreau, C., Driezen, P., Hyland, A., Borland, R., Cummings, K.M., Hastings, G.B., MacKintosh, A.M., \& Laux, F.L. (2006). Methods of the International Tobacco Control (ITC) Four Country Survey. Tobacco Control, 15(suppl III):iii12-18.

Wakefield, M., Germain, D., Durkin, S., \& Henriksen, L. (2006). An experimental study of effects on schoolchildren of exposure to point-of-sale cigarette advertising and pack displays. Health Education Research, 21: 338-347.

Wakefield, M., Germain, D., \& Henriksen, L. (2008). The effect of retail cigarette pack displays on impulse purchase. Addiction, 103: 322-328.

Wilkinson, J. B., Mason, B., \& Paksoy, C. H. (1982). Assessing the impact of shortterm supermarket strategy variables. Journal of Marketing Research, 19: 72-86.

WHO. Report on the Global Tobacco Epidemic, 2008: The MPOWER package. Geneva: World Health Organization; 2008. 